\title{
Análisis bioinformático de las rutas pks y fas en plantas y uso de inductores exógenos sobre la producción de acetogeninas en guanábana cultivada in vitro
}

\section{Bioinformatic analysis of pks and fas pathways in plants and use of exogen inductors on the production of acetogenins from soursop cultivated in vitro}

\author{
SÁNCHEZ-RAMOS, Sanjuana ${ }^{1}{ }^{\dagger}$, CARRILLO-LANDELL, Felipe Guadalupe ${ }^{1}$, CRUZ-JIMENEZ, \\ Gustavo $^{2}$, GONZÁLEZ-IBARRA, Alan Alexander ${ }^{2}$
}

${ }^{I}$ Instituto Tecnológico Superior de Irapuato

${ }^{2}$ Universidad de Guanajuato

ID $1^{\text {er }}$ Autor: Sanjuana, Sánchez-Ramos / ORC ID: 0000-0001-6835-0494

ID $1^{\text {er }}$ Coautor: Felipe Guadalupe, Carrillo-Landell / ORC ID: 0000-0002-2826-4759

ID $2^{\text {do }}$ Coautor: Gustavo, Cruz-Jimenez / ORC ID: 0000-0002-4355-0403

ID $3^{\text {er }}$ Coautor: Alan Alexander, González-Ibarra / ORC ID: 0000-0003-3740-5055

DOI: 10.35429/JBEB.2019.9.3.19.28

Recibido 16 de Julio, 2019; Aceptado 15 Septiembre, 2019

\begin{abstract}
Resumen
Objetivos. Analizar el efecto en la producción de acetogeninas de Annona muricata cultivada in vitro mediante Biorreactores de Inmersión Temporal (BITs) promovido por el uso de inductores exógenos propuestos de un análisis bioinformático. Metodología. Se realizó un análisis bioinformático en el sitio KEGG de las rutas metabólicas de plantas de la Policétido Sintetasa (PKS) y de la Ácido Graso Sintetasa (FAS) de las cuales se derivan las acetogeninas. Se realizaron cinco tratamientos en los BITs con explantes de guanábana; 1) BAP, 2) BAP + AAs 3) $\mathrm{BAP}+\mathrm{AAs}+$ Putrescina, 4) BAP + IAA y 5) BAP + IAA + Citrato. BAP e IAA son hormonas vegetales, AAs es una mezcla de tres aminoácidos cetogénicos, Putrescina y Citrato son inductores de PKS y FAS. Contribución. Se logró dar seguimiento al cultivo de explantes de guanábana usando BITs de los 5 tratamientos durante 8 semanas sin presentar contaminación aparente. La observación de brotes comenzó a partir de la semana 6 en el tratamiento 1 y 2 pero no en el 3 a lo largo de las 8 semanas, siendo la putrescina más que un inductor un factor de estrés para el explante ya que se necrosaron. Los tratamientos 4 y 5 sólo se monitorearon hasta la tercera semana y no se recopiló información sobre brotación. Se desarrollo un método para analizar el perfil de acetogenianas por HPLC-PDA.
\end{abstract}

Guanábana, Acetogeninas, Cultivo in vitro

\begin{abstract}
Goals. To analyze the effect on the production of acetogenins of Annona muricata cultivated in vitro by means of Temporary Immersion Bioreactors (BITs) promoted by the use of exogenous inducers proposed from a bioinformatic analysis. Methodology. A bioinformatic analysis was carried out at the KEGG site of the metabolic pathways of polyketide synthetase (PKS) and fatty acid synthetase (FAS) plants from which acetogenins are derived. Five treatments were performed in the BITs with soursop explants; 1) BAP, 2) BAP + AAs 3) BAP + AAs + Putrescine, 4) BAP + IAA and 5) BAP + IAA + Citrate. BAP and IAA are plant hormones, AAs is a mixture of three ketogenic amino acids, Putrescine and Citrate are inducers of PKS and FAS. Contribution. The cultivation of soursop explants was monitored using BITs of the 5 treatments for 8 weeks without apparent contamination. Sprout observation started from week 6 in treatment 1 and 2 but not in 3 over 8 weeks, with putrescine being more than an inducer a stress factor for the explant as they became necrotic. Treatments 4 and 5 were only monitored until the third week and no information on sprouting was collected. Differences in the profile of acetogenins by HPLC-PDA were observed between soursop leaves to $e x$ vitro and in vitro and between treatments 1,2 and 3 .
\end{abstract}

Soursop, Acetogenins, in vitro culture

\footnotetext{
* Correspondencia del Autor (sansanchez@itesi.edu.mx)

$\dagger$ Investigador contribuyendo como primer autor
} 


\section{Introducción}

La Annonacea es una de las familias de plantas tropicales en la que sus estudios farmacológicos y fitoquímicos sobre esta especie se han incrementado en los últimos 15 años. Esto es gracias al descubrimiento de las acetogeninas de Anonáceas, ya que estos contienen compuestos naturales con una gran variedad de actividades biológicas como el de apoptosis celular y biopesticida principalmente. (Santos, 2001).

Debido a la importancia que está teniendo la A. muricata dentro de la industria alimenticia, se está mostrando un gran interés, esto es debido a que contiene varios compuestos activos que se encuentran tanto en la corteza, hojas, raíz y semillas. Estos metabolitos son secundarios y tienen la capacidad de inducir apoptosis (muerte celular programada) en células cancerosas, además de la actividad biopesticida siendo estas dos las razones primordiales. (Ríos, 2003).

En el año 2006 Quispe y colaboradores prueban un compuesto denominado Muricina $\mathrm{H}$, sustancia que fue evaluada en líneas celulares H460 (cáncer de pulmón) y fibroblastos normales de ratón, en donde se observó un efecto citotóxico significativo en la línea celular H460. En el año 2007, se probó un extracto etanólico al 95\% de hojas secas en líneas celulares de adenocarcinoma de pulmón (H-460) y gástrico (C-678) obteniendo resultados significativos de citotoxicidad (Quispe, 2007).

Durante el 2009, en el trabajo de Oviedo et al., se observó el efecto de un extracto y fracción alcaloidal de Guanábana sobre dos líneas celulares como C67 y C95.9, mostrando efectos citotóxicos a concentraciones mayores de $1 \mathrm{mg} / \mathrm{mL}$ para el caso de la línea celular de vejiga y $2 \mathrm{mg} / \mathrm{mL}$ en la línea celular de leucemia. Además, concluyeron que el consumo de alcaloides provenientes de $A$. muricata producían un efecto neurotóxico in vitro y un efecto ansiolítico en modelo de ratones ICR.

El sistema BIT, es diseñado mediante dos recipientes transparentes de vidrio o plástico, uno de los cuales contiene el material vegetal, y el otro sirve como contenedor de medio de cultivo líquido. Los dos recipientes se conectan mediante mangueras de silicona, el flujo aire pasa a través de filtros de $0.02 \mu \mathrm{m}$.
La presión que ejerce el aire permite que el medio líquido pase de un recipiente a otro, sumergiendo totalmente las plántulas. Posteriormente, el flujo de aire se invierte para devolver el medio líquido a su recipiente de origen, este proceso es controlado mediante válvulas de solenoide y temporizadores, que facilitan establecer el tiempo de contacto o inmersión de las plántulas con el medio líquido.

Con el sistema BIT se puede solucionar problemas habituales que se presentan en la micropropagación tradicional en medio líquido y semisólido, tales como la hiperhidricidad y baja calidad de los propágulos. Además se evita trasplantar o subcultivar las plántulas, y es importante resaltar que se genere una mayor transferencias de gases, gracias a la alimentación de aire al sistema y se disminuyen los trastornos fisiológicos, conservando la integridad morfológica del tejido o planta (Berthouly y Etienne, 2005; et al., 2003) .

\section{Marco teórico}

\section{Generalidades de la Annona muricata}

Actualmente, aún no se sabe con certeza el lugar de origen de la planta de A. muricata, esta especie se encuentra difusa de forma silvestre como cultivada en los trópicos de América y de África Occidental, también es cultivada en el Sureste de China, Australia, Sur de Florida, y desde México hasta Brasil. Crece desde los $0 \mathrm{~m}$ hasta los $1000 \mathrm{~m}$ de altura; su producción comercial se ha desarrollado altamente en Brasil, Venezuela, Costa Rica y otros países ya sean para su consumo local y también para la exportación. Como resultado de esto, se tiene una variación tanto en el tamaño del fruto como en el contenido de los azúcares. (Ríos, 2003).

Esta especie crece muy bien en climas tropicales que son los cálidos y húmedos. Tiene una gran adaptabilidad para los distintos tipos de suelos ya que también se desarrolla dentro de $\mathrm{pH}$ ligeramente ácido de 5.5 a 6.5. El nombre científico de la Guanábana es Annona muricata, el peso de este fruto es aproximadamente entre 1 y $2.5 \mathrm{~kg}$. Su sabor se caracteriza por ser agridulce y está recubierto de una cáscara fina, espinosa de color verde oscuro, la pulpa es de color blanco y además muy blanda. 


\section{Estudio Fitoquímico de la Annona muricata}

Con la finalidad de poder aprovechar de una manera más eficiente todos los recursos naturales para así poder encontrar productos naturales con aplicación terapéutica, algunos organismos internacionales como lo es el Instituto Nacional del Cáncer (EUA) realizan actualmente estudios fitoquímicos de la flora mundial.

En los últimos 15 años el estudio de las annonaceas ha sido intensificado, por lo tanto, se han aislado metabolitos secundarios entre ellos se encontraron: alcaloides, ácidos grasos, amidas y acetogeninas, todos estos contenidos dentro de la corteza, también en las semillas, el tallo y finalmente las hojas.

Las acetogeninas son metabolitos secundarios, provenientes de las plantas de la familia Annonaceae (Alali, 1998). Estas acetogeninas han sido utilizadas en diversas actividades como fungicidas, bactericidas, antihelmínticos, antivirales e insecticidas contra varios insectos (coleópteros, hemípteros, phthyrápteros, lepidópteros, blátidos y otros). Además del efecto antiparasitario y antitumoral que contiene, las acetogeninas son muy importantes por la baja tasa de resistencia que podrían generar los insectos frente a ellas. (RobledoReyes, 2008). De la annonaceae, se han reportado numerosas acetogeninas aisladas e identificadas tales como la uvaracina, la primera que fue aislada de la planta de Uvaria accuminata en 1982 (García, 2009).

Las acetogeninas poseen principalmente dos actividades biológicas muy importantes que son: actividad citotóxica y biopesticida. Para la actividad citotóxica, se ha demostrado que las acetogeninas inhiben a la enzima NADH que se encuentra situada dentro del Complejo I de la cadena respiratoria mitocondrial, el objetivo principal de esta acción es el de agotar el ATP y como consecuencia de esta acción produce en las células una muerte programada (apoptosis), se ha confirmado que las acetogeninas buscan selectivamente las células cancerígenas para atacarlas y las células normales permanecen intactas (González, 2011).

\section{Separación e identificación de acetogeninas}

Las acetogeninas son solubles en la gran mayoría de solventes orgánicos. Varias técnicas para realizar la extracción y el aislamiento de las acetogeninas emplean el uso de éter, hexano, metanol y fluidos supercriticos seguido por la partición en disolventes de diferente polaridad o cromatografía de líquidos de fase reversa para aislar los componentes. (Sevser, 1994)

Para poder realizar la identificación de las diferentes acetogeninas existentes es muy importante conocer las diferentes configuraciones como, la posición de los anillos de tetrahidrofuranos y de los diferentes grupos funcionales, así como la masa exacta de cada estructura. Esto es posible hoy en día gracias a técnicas como lo es la resonancia magnética nuclear, infrarrojo y espectrometría de masas. (Duret, 1997, Skoog, 1995, Herrera, 2007).

La polaridad es controlada por los anillos tetrahidrofuranos (THF) y otros grupos funcionales, así como los hidroxilos, cetonas, epóxidos y dobles enlaces, y algunas veces depende de la posición del anillo THF y de los grupos funcionales a lo largo de la cadena (Herrera, 2007).

\section{Propagación por cultivo de tejidos}

El desarrollo de las técnicas de cultivo demuestra que es ventajosa por la rapidez en la propagación de la planta, consiste en aislar una porción de la planta (explante) bajo condiciones asépticas, sea esta una célula, un tejido o un órgano, y proporcionarle artificialmente las condiciones físicas y químicas apropiadas para que las células expresen su potencial intrínseco o inducido. La micropropagación in vitro es una técnica más elaborada, pues requiere de laboratorios especializados para su realización. Sin embargo, este método puede ser usado no solo para la producción de mudas sanas y de buena calidad, sino también, cuando existe escasez de material para la plantación.

\section{Sistema de Inmersión Temporal}

Es un sistema que está constituido por dos frascos, de los cuales, uno se utiliza para colocar el inoculo y en el otro frasco, el medio de cultivo. Ambos frascos poseen dos vías de acceso: la primera es para la ventilación y la segunda para el intercambio de medio de cultivo entre ambos frascos.

SÁNCHEZ-RAMOS, Sanjuana, CARRILLO-LANDELL, Felipe Guadalupe, CRUZ-JIMENEZ, Gustavo, GONZÁLEZ-IBARRA, Alan Alexander. Análisis bioinformático de las rutas pks y fas en plantas y uso de inductores exógenos sobre la producción de acetogeninas en guanábana cultivada in vitro. Revista de Ingeniería Biomédica y Biotecnología. 2019 
En cada frasco, la circulación del aire es esterilizada mediante filtros hidrofóbicos (Escalona et al. 1999).

El biorreactor es ampliamente usado en el cultivo de varios microorganismos como células microbianas, animales y vegetales con el fin de producir distintos metabolitos o células (Takayama \& Akita, 2000). El uso del biorreactor en la propagación de plantas es ventajoso para incrementar la eficiencia de producción de brotes debido a que resuelve muchos de los problemas que encontramos en las técnicas de cultivo de tejidos convencional, en las que se usan medios semisólidos y sólidos como son:

- Necesidad de gran cantidad de frascos.

- Mayor cantidad de mano de obra.

- Gran cantidad de herramientas e instrumentos de laboratorio.

- $\quad$ Necesidad de gran cantidad de espacio.

- Los méritos de uso de biorreactores en propagación de plantas son los siguientes (Takayama \& Akita, 1994):

- Es fácil producir un gran número de explantes.

- El manipuleo de los cultivos como la siembra y cosecha es sencillo, lo cual ahorra tiempo y recursos.

- Los cultivos están siempre en contacto con el medio y esta es la causa de estimulación en la toma de nutrientes lo cual resulta en la estimulación de la tasa de crecimiento.

- Aireación forzada (abastecimiento de oxígeno) estimula la tasa de crecimiento y alcanzar el incremento de la biomasa.

- Desaparición de la dominancia apical, debido a que los cultivos se mantienen en movimiento, propiciando el crecimiento de numerosos brotes hasta la formación de explantes.

\section{Impacto o beneficio}

Este proyecto impacta no sólo en el tratamiento de enfermedades (cáncer) con el uso de sustancias naturales, sino que busca aumentar los rendimientos de metabolitos secundarios vegetales con actividad citotóxica mediante la utilización de una metodología de propagación de tejidos, confiable, segura y ambientalmente amigable sin sacrificar ejemplares que forman parte de un ecosistema.

\section{Metodología}

\section{Medio de cultivo}

Al medio de cultivo líquido de MS se le añadieron $30 \mathrm{~g} / \mathrm{L}$ de sacarosa (concentración normal) y con el doble de sacarosa (2X) y sacarosa a la mitad (0.5X), así mismo se adicionó $1 \mathrm{mg} / \mathrm{mL}$ de 6-bencilaminopurina (BAP). El pH del medio se ajustó a 5.8 con $\mathrm{NaOH}$ o $\mathrm{HCl}$ según sea el caso. A esta preparación se le añadierón unas gotas de nanopartículas de plata para la esterilización del medio de cultivo, se calientó a una leve ebullición durante 5 minutos.

\section{Esterilización de Biorreactores de Inmersión Temporal}

Los biorreactores se lavarón con cloro comercial al 5\%, se adicionarón $3 \mathrm{~mL}$ de cloro por cada 100 $\mathrm{mL}$ de agua y jabón líquido para trastes (3g de jabón por cada litro de agua). Se enjuagarón por completo y se dejarón boca abajo durante 20 minutos. Las tapas y tuberías se esterilizarón en autoclave. Se ensamblarón frascos, tapas y tuberías en la campana de flujo laminar.

\section{Material vegetal y estimulación de estrés}

Los tallos jóvenes de plantas de Annona muricata se lavaron con agua corriente y se esterilizaron en su superficie con una solución de hipoclorito de sodio al 1,0\% (control) y/o con nanopartículas de plata durante 30 segundos. Se colocaron en los biorreactores de $1 \mathrm{~L}$ que contenían $500 \mathrm{~mL}$ de MS (Murashige y Skoog, 1962) en medio liquido complementado con 1 $\mathrm{mg} / \mathrm{mL}$ de 6-bencilaminopurina y sacarosa $1 X$, $2 \mathrm{X}$ y $0.5 \mathrm{X}$. A estos medios con distintos niveles de sacarosa se le añadieron factores bióticos estimulantes de estrés. El pH del medio se ajustó a 5.8 unidades.

\section{Operación de BITs y Micropropagación}

Los biorreactores se llenaron con $500 \mathrm{~mL}$ del medio apropiado (tratamientos) y con los explantes en un entorno estéril. Finalmente, se realizaron las conexiones entre los biorreactores y un sistema de bombeo neumático. El sistema de bombeo neumático fue controlado por una unidad de control automático para la regulación del tiempo y frecuencia de inmersión de explantes en el medio. 
Todos los biorreactores independientemente de los tratamientos del medio líquido fueron expuestos a una duración y frecuencia de inmersión fija. El fotoperiodo también se mantuvo fijo. Después de 5 a 6 semanas de cultivo de los explantes bajo los distintos tratamientos del medio líquido (con y sin factores de estrés y distintos niveles de sacarosa), se registraron el peso fresco, el peso seco, la longitud del brote, el diámetro del tallo, el número de hojas y el área foliar. El área foliar se midió con un medidor de área foliar (Skye Co, Reino Unido).

\section{Metodología}

El análisis bioinformáticó se realizó en el sitio web KEEG con el fin de analizar y comparar las rutas metabólicas que utilizaran como sustrato el acetil-CoA ya que este es componente esencial para las rutas PKS y FAS encargadas de la producción de ácidos grasos y policétidos, estructura general de las acetogeninas encontradas en A. muricata, se reconocierón inductores que regulan la activación de estas para lograr inactivarlas con el fin de dejar la mayor concentración de acetil-CoA para la síntesis de ácidos graso y policétidos con el fin de que esto maximizará la producción de acetogeninas en Annona muricata cultivada in vitro.

\section{Medio de cultivo MS}

Para la preparación del medio de cultivo es necesario que se lleven a cabo las siguientes soluciones:

Solución A: $19.0 \mathrm{~g}$ de $\mathrm{KNO}_{3}$, pesar $16.5 \mathrm{~g}$ de NH4NO, depositar ambos compuestos en un matraz aforado de $100 \mathrm{~mL}$ y aforar con agua de osmosis

Solución B: $1.8 \mathrm{~g}$ de $\mathrm{MgSO}_{4}$ o $3.7 \mathrm{~g}$ de $\mathrm{MgSO}_{4} * 7 \mathrm{H}_{2} \mathrm{O}, 0.169 \mathrm{~g}$ de $\mathrm{MnSO}_{4} * \mathrm{H}_{2} \mathrm{O}, 0.086 \mathrm{~g}$ de $\mathrm{ZnSO}_{4} * 7 \mathrm{H}_{2} \mathrm{O}, 0.00025 \mathrm{~g}$ de $\mathrm{CuSO}_{4} * 5 \mathrm{H} 2 \mathrm{O}$, disolver todos los compuestos en un matraz aforado de $100 \mathrm{~mL}$ y aforar con agua de osmosis Solución C: $0.00025 \mathrm{~g}$ de $\mathrm{CoCl}_{2} * 6 \mathrm{H}_{2} \mathrm{O}$ o $0.00025 \mathrm{~g}$ de $\mathrm{CoCl} 2 * 2 \mathrm{H} 2 \mathrm{O}, 0.0083 \mathrm{~g}$ de $\mathrm{KI}$, $3.32 \mathrm{~g}$ de $\mathrm{CaCl} 2$ o $4.40 \mathrm{~g}$ de $\mathrm{CaCl} 2 * 2 \mathrm{H} 2 \mathrm{O}$, disolver todos los compuestos en un matraz aforado de $100 \mathrm{~mL}$ y aforar con con agua de osmosis
Solución E: $0.27 \mathrm{~g}$ de $\mathrm{FeSO} 47 \mathrm{H} 2 \mathrm{O}$ y disolver en $20 \mathrm{~mL}$ de agua de osmosis previamente calentada, esto para evitar que el $\mathrm{Fe}$ se precipite, $0.37 \mathrm{~g}$ de Na2EDTA o $0.41 \mathrm{~g}$ de $\mathrm{Na} 2 \mathrm{EDTA} * 2 \mathrm{H} 2 \mathrm{O}$ y disolver en $20 \mathrm{~mL}$ de agua de osmosis previamente calentada., agregar las dos soluciones en un matraz aforado de $100 \mathrm{~mL}$ $\mathrm{y}$ aforar con agua de osmosis previamente calentada, cubrir el matraz aforado con aluminio. Solución F: $0.02 \mathrm{~g}$ de Glicina, $1.0 \mathrm{~g}$ de Mioinositol, $0.005 \mathrm{~g}$ de Ácido nicotínico, $0.005 \mathrm{~g}$ de Piridoxina $\mathrm{HCl}, 0.001 \mathrm{~g}$ de Tiamina HCL, disover todos los compuestos en un matraz aforado de $100 \mathrm{~mL}$ y aforar con agua de osmosis. Medio MS

Preparadas las soluciones se toman 10 $\mathrm{mL}$ de cada una y se depositan en un matraz aforado de $1 \mathrm{~L}$, posteriormente se le agregan de 20 a $30 \mathrm{~g}$ de sacarosa al matraz y se afora

Solución Stock de BAP $[1 \mathrm{mg} / \mathrm{mL}]$

Se Pesaron 10mg de BAP y diluir en $10 \mathrm{~mL}$ de agua de osmosis, ajustar el $\mathrm{pH}$ a $5.8 \pm 0.1 \mathrm{con}$ $\mathrm{NaOH}$ o $\mathrm{HCl}$, según sea el caso, calentar a ebullición leve por $5 \mathrm{~min}$, añadir $2 \mathrm{~mL}$ de solución Stock de BAP al matraz aforado que contiene el medio MS

\section{Biorreactores}

Los biorreactores se lavaron con cloro comercial al 5\%, se adicioóa $3 \mathrm{ml}$ de cloro por cada $100 \mathrm{ml}$ de agua.

Material vegetal

Los brotes axilares de Guanábana (Annona muricata) se lavaron con agua corriente y se secaron, se seleccionaron las hojas y tallos juveniles y proceder a cortar con una longitud de $1 \mathrm{~cm}$ cada tallo y hoja.esterilizar las hojas y el tallo con solución tween y cloro en un tubo falcón; mediante una agitación manual de 20 $\min$.

\section{Micropropagación}

Los biorreactores, se conectaron con filtros de PTFE estériles, se llenaron con $500 \mathrm{ml}$ del medio apropiado y los explantes preparados previamente en un entorno estéril se depositaron en el biorreactor. Siendo 5 hojas y tallos por cada biorreactor. 
Finalmente, se conectaron tubos de plástico entre los biorreactores y un sistema de bombeo neumático. Todos los biorreactores, independientemente de las especies de plantas, se expusieron a aireación e inmersión con el mismo régimen.

La frecuencia de inmersión se ajustó a tres veces por día durante periodos fue de 5-10 minutos cada 8 horas. Con un fotoperiodo de 16 hrs luz y 8 hrs oscuridad.

\section{Resultados}

\section{Análisis Bioinformático}

En la biosíntesis general de plantas mostrada en la Figura 1 podemos observar como el acetilCoA es un precursor de los policétidos, las acetogeninas pertenecen a la familia de los policétidos, por ende, para favorecer la producción de estas es necesaria la conservación de Acetil-CoA.

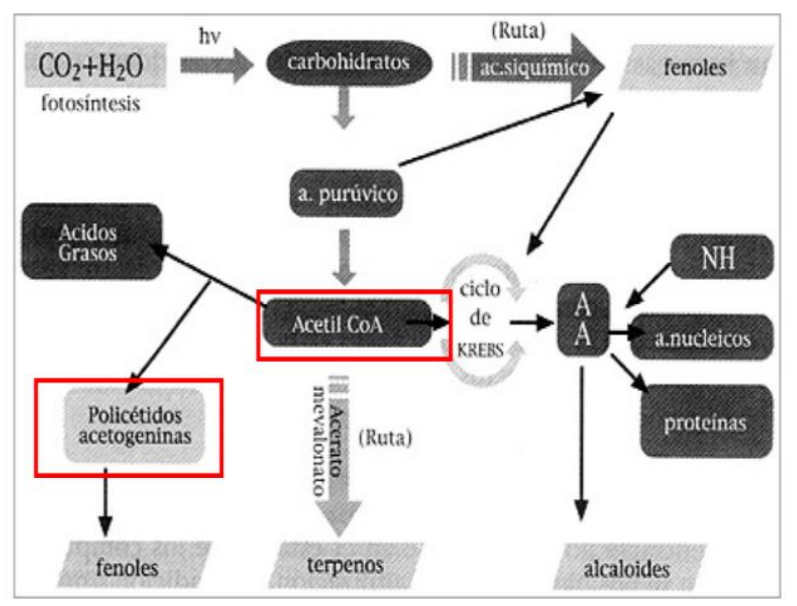

Figura 1 Biosíntesis general de plantas

Se seleccionó un organismo modelo registrado en la base de datos de KEGG ya que A. muricata no se encuentra reportada actualmente. El organismo seleccionado fue Vitis vinífera (Uva de vino).

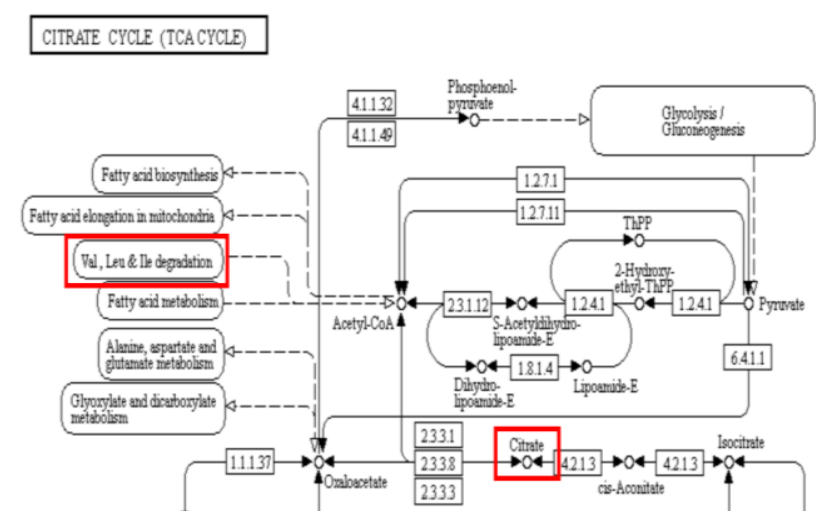

Figura 2 Ciclo del citrato (KEGG)

En la Figura 2 se muestra el ciclo del citrato para Vitus vinifera (uva de vino) y se identifica como el acetil-CoA se transforma en citrato y viceversa, así también se presenta la relación de los aminoácidos (Val,Leu e Ile) con el acetil-CoA. Una vez revisado esto la selección de los inductores de acetogeninas fueronCitrato, Putrecina, Isoleucina, Alanina, Valina.

\section{Cultivo in vitro}

En las siguientes ilustraciones se muestra los cultivos in vitro de A. muricata del primer sistema de biorreactores montado, en el cual se llevaron a cabo 2 tratamientos y 1 control, el primer tratamiento consta de hormona BAP y aminoácidos (AA's), y el segundo tratamiento de BAP+AA's+Putrecina y el control que solo contiene hormona BAP.

\section{$\mathbf{B A P + A A}$ 's}

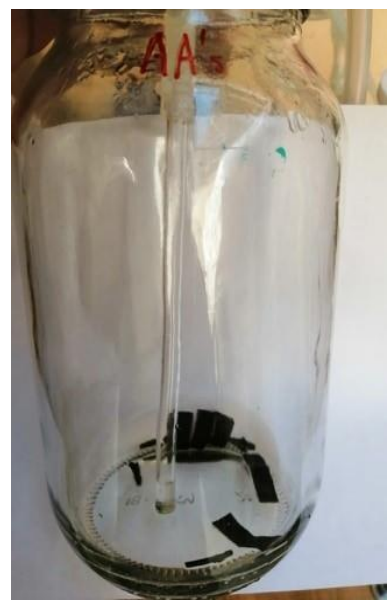

A)

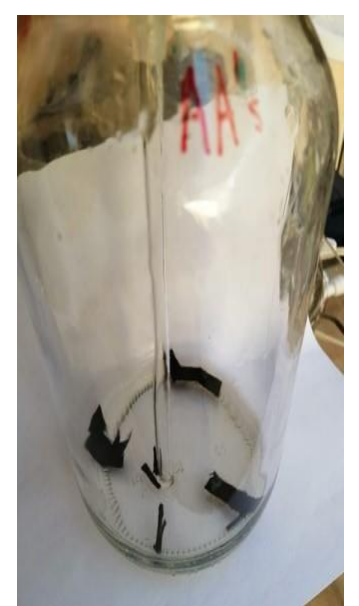

B)
Figura 3 Primer tratamiento del primer sistema de biorreactores, en la figura B se observan brotes en los tallos 


\section{BAP+AA's+Putrecina}
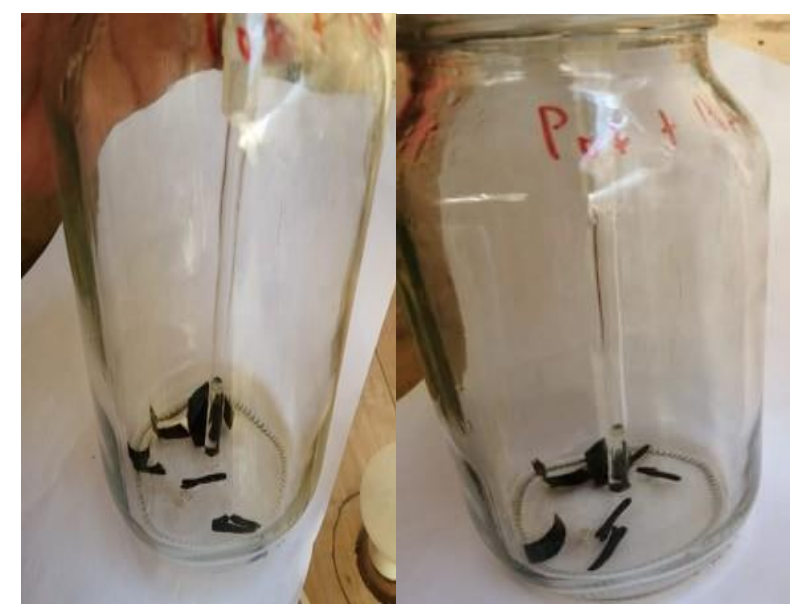

A)

B)

Figura 4 Segundo tratamiento del primer sistema de biorreactores, en ambas ilustraciones no se observa el crecimiento de brotes

\section{Control (BAP)}

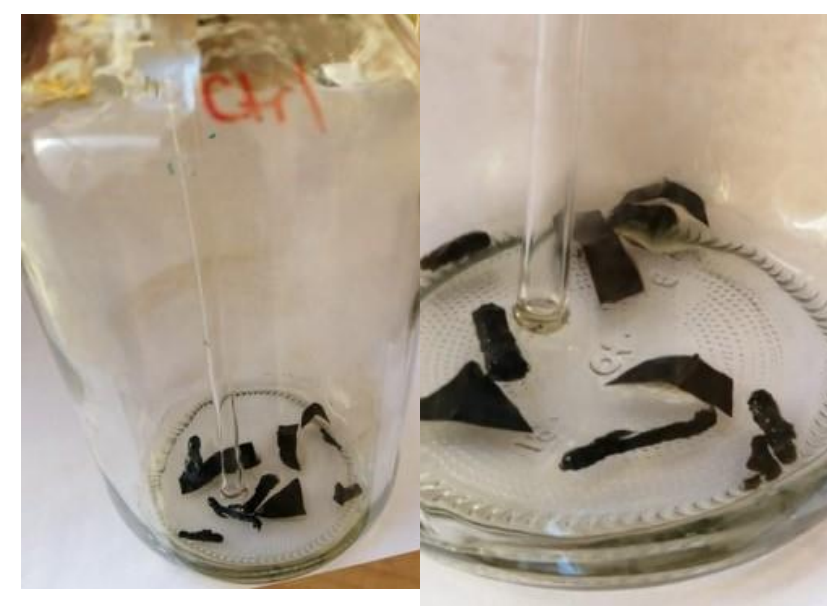

Figura 5 Control del primer sistema de biorreactores, en ambas figuras se observa el crecimiento de brotes en los tallos de la planta

El crecimiento de brotes en los tallos se dio únicamente en el primer tratamiento y en el control lo que indica que la Putrecina no favorece el crecimiento de la planta en el cultivo in vitro, el crecimiento de los brotes se comenzó a apreciar a partir de la 6ta semana del tratamiento.

En las siguientes graficas se indica la presencia de brotes en los tallos u hojas en los distintos tratamientos, en donde 1:No hay brotes y 2:Si hay brotes, y la semana en la cual se comenzaron a apreciar dichos brotes.

\section{Tratamiento 1 Semana vs Brotes}

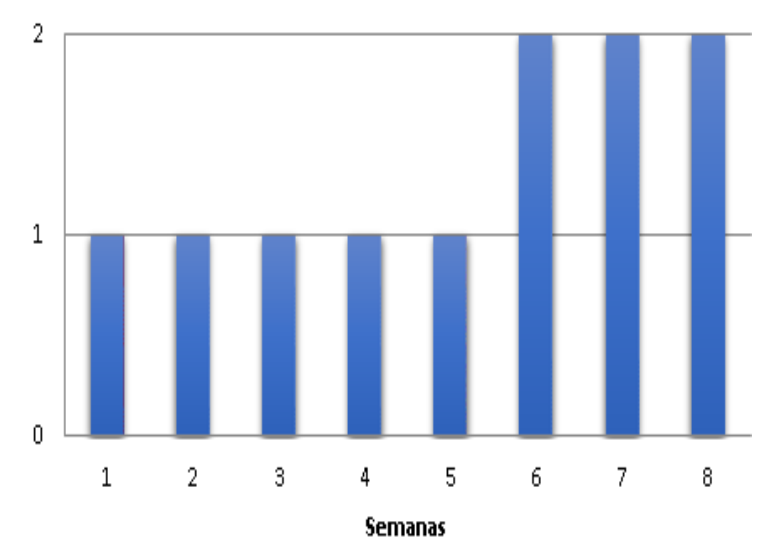

Gráfico 1 Tratamiento 1: Semana vs Brotes

Tratamiento 2 Semanas vs Brotes

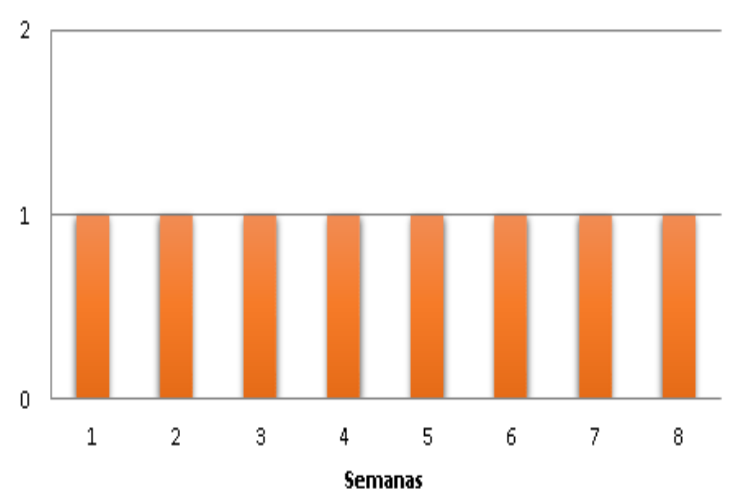

Gráfico 2 Tratamiento 2: Semanas vs Brotres

\section{Control Semanas vs Brotes}

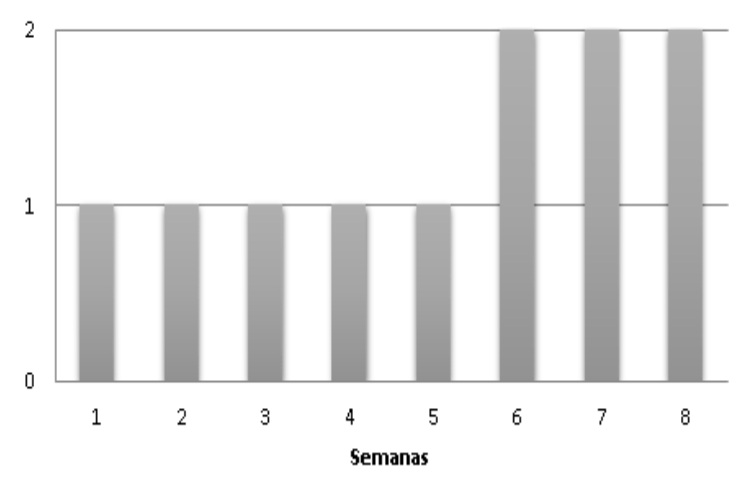

Gráfico 3 Control: Semanas vs Brotes

En la Figura 4 se muestran los cultivos in vitro de A.muricata con los tratamientos combinados 6-N-Bencilaminopurina (BAP), Acido-3-indolacetico (IAA) y la combinación de estos con citrato. 


\section{BAP+IAA+Citrato}

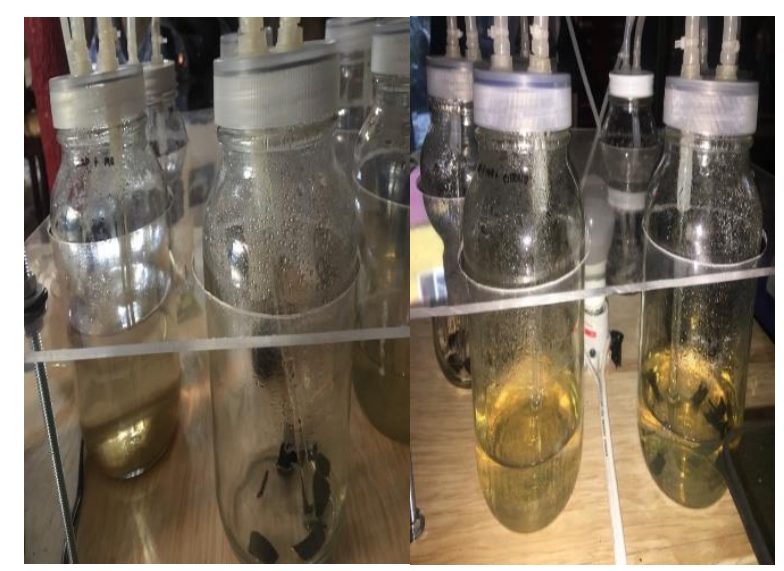

Figura 4 Tratamientos del segundo biorreactor

\section{Análisis de acetogeninas por HPLC-PDA}

Preparación de extractos Para los extractos acuosos: disolver en agua destilada el tamizado y dejar hervir durante 30 minutos. Una vez transcurrido el tiempo dejar enfriar y centrifugar a $4000 \mathrm{rpm}$ por 5 minutos. Esterilizar mediante filtración. Guardar en frascos ámbar a $4^{\circ} \mathrm{C}$. Para el extracto etanólico de muestra y realizar una extracción con etanol al 95\% caliente. Dejar enfriar y realizar una filtración en frio y una evaporación para obtener un extracto etanólico concentrado.

Debido al carácter apolar y tamaño de las acetogeninas, estas moléculas suelen ser aptas para su separación y análisis por cromatografía de líquidos en fase reversa con detector de arreglos de fotodiodos (HPLC-PDA) cuando se encuentran en altas concentraciones en la muestra. Se utilizó un HPLC altus A-10 con un detector PDA, automuestreador y degasificador. La columna fue una C18 hypersil $(250 \times 10$, 5um) de Thermo.

La separación de las acetogeninas, se utilizó el siguiente gradiente de elución con dos fases móviles (A - Agua y B - Metanol): 0 - 30 $\min 70 \% \mathrm{~B}, 30-40 \min 95 \% \mathrm{~B}, 40-60 \mathrm{~min}$ $95 \%$ B. El flujo total fue de $1 \mathrm{~mL} / \mathrm{min}$ y un volumen de inyección de $50 \mathrm{uL}$. Se adquirió los datos a una longitud de onda de $220 \mathrm{~nm}$ con una rendija de $4.8 \mathrm{~nm}$.

Con el objetivo de demostrar la capacidad del método para analizar los perfiles de acetogeninas de las muestras, se inyecto a la columna $50 \mathrm{uL}$ de un extracto metanólico de hojas de A. muricata.
La figura 1 muestra el cromatograma donde se observan la elución de algunos compuestos a partir del minuto 48 , los cuales pueden corresponder a las acetogeninas debido a las altas concentraciones de metanol en el gradiente y altos tiempos de retención.

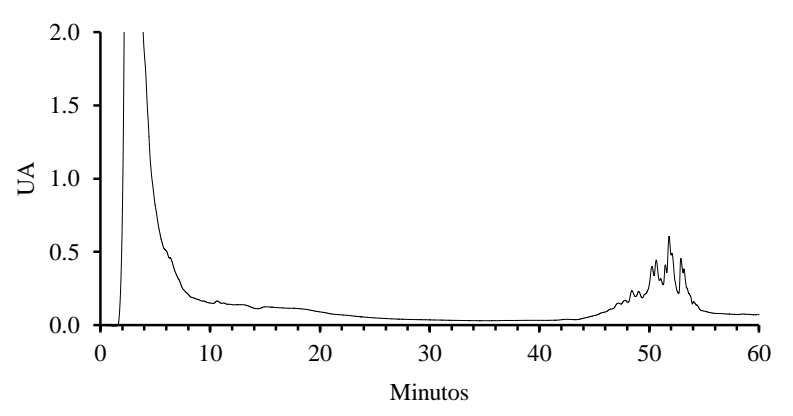

Figura 1 Cromatograma obtenido de los extractos metanolicos de la hoja de A. muricata a una longitud de onda de $220 \mathrm{~nm}$

\section{Discusiones}

En el ciclo del citrato se aprecia la relación de este con el acetil- CoA (KEGG), por esto cuando el medio se enriquece con citrato, las plantas no tendrán la necesidad de convertir Acetil- CoA en este, favoreciendo la producción de acetogeninas. Así también la producción de estos policétidos se vera favorecida por la presencia de los aminoácidos seleccionados ya que estos promueven la producción de AcetilCoA.

Las poliaminas (PAs) como la putrecina son conocidas como indicadores del estrés en plantas además de su toxicidad. Se sabe que la disminución de PAs, inducirá un alza en los niveles de espermidina $\mathrm{N}$-acetil transferasa (SSAT) como respuesta para la biosíntesis de poliaminas y el acetil-CoA.

En estudios posteriores se ha analizado la combinación de hormonas como BAP e IAA en vegetales para acelerar el crecimiento del cultivo en un menor tiempo (Taha, 2008). Por esto se seleccionaron estos tratamientos para ver si favorecían el crecimiento de A.muricata ya que no se han reportado esta especie cultivada de manera in vitro. Así también se sabe que el cultivo de planta in vitro tiene una duración aproximada de 4 semanas (Taha, 2008) pero para A. muricata se observaron brotes hasta la 6 ta semana 


\section{Conclusión}

El análisis bioinformático ayudó a la selección de inductores para favorecer el crecimiento de la A. muricata en un cultivo in vitro y con esto se pretende aumentar la producción de acetogeninas. Los resultados obtenidos mostraron que efectivamente los aminoácidos favorecen el crecimiento de brotes en los tallos de A. muricata. Por otro lado, no se pudo observar bajo estas condiciones el perfil de acetogeninas con la técnica de HPLC-PDA debido a la baja concentración de estos compuestos en los extractos, esto puede obedecer a la poca biomasa obtenida en los biorreactores.

Estudios previos mostraron que el tiempo de propagación en cultivo in vitro para plantas es de 4 a 5 semanas, sin embargo, en este estudio fue de 6 semanas debido a que la hormona utilizada (BAP) en el primer sistema ya se encontraba caducada y se cree que se retardo el tiempo de propagación debido a este factor.

\section{Referencias}

Alali, F. K. (1998). Annonaceous acetogenins as natural pesticides: Potent toxicity against insecticide-sysceptible and insecticide-resistant German cockroaches (Dictyoptera: Blattellidae). Journal of economic entomology, 91(3), 641649.

Basail, M., Medero, V., Ventura, J., Otero, E., Torres, M., López, J., Cabrera, M., Santos, A., Rayas, A.,

Bauta, M., Beovidez, Y. (2012). Multiplicación del clon de banano FHIA-18 (AAAB) en Sistema de Inmersión Temporal. Revista Colombiana Biotecnología, XIV (1): 8-19 p.

Berthouly, M., y Etienne, H. (2005). Temporaly immsersion system: a new concept for use liquid médium in mass propagation. In Liquid Culture System for in vitro Plant Propagation (pp. 165195).

Duret, P.; WAECHER, R.; CAVE, A. (1997). Atemoyin-1 and 2-two Mono- Tetrahidrofuran lactone Acetogenins from the seeds of Annona atemoya. Plant. Med. 22-28.
Escalona M. 1999. Propagación de la piña [Ananas comosus (L.) Merr.] en sistemas de inmersión temporal. Tesis para aspirar al grado científico de Doctor en Ciencias Agrícolas. Universidad de Ciego de Ávila, Centro de Bioplantas. Cuba. 102 p.

HERRERA, E. (2007). Obtención y Caracterización de la Materia Insaponificable del Aceite de Crisálida de Bombix Mori L.

GARCIA, K. (2009). Aislamiento y caracterización estructural de acetogeninas obtenidas de semillas de Annona cherimolia y Annona muricata. Evaluación genotóxica y potencial quimioterapéutico. Tesis. Instituto Politécnico Nacional, Escuela Nacional de Ciencias Biológicas. México, D.F. Pílamo I. Tesis. Universidad Tecnológica de Pereira. p. 85.

Georgiev, V., Schumann, A., Pavlov, A., Bley, T. (2014). Temporary inmertion systems in plant biotechnology. Engieering in life sciences, Estados Unidos, 14: 607621 p.

González, A. L. (2011). Annonaceaes, plantas antiguas, estudios recientes. Tuxtla Gutiérrez, Chiapas, México: UNICACH-Universidad de Ciencias y Artes de Chiapas

Gueguim, E., Oloke, J., Lateef, A., Azanfack, R., Adeyemi, A. (2010). Implementation details of computerized temporary inmersion bioreactor (TIB): A fermentation case of Pleurotus pulmonarius. Biotechnol. \& Biotechnol, Nigeria, 24 (4): 2149-2153 p.

Juárez, A., Manjarrez, E., Barrón, H. (2011). Diseño de un biorreactor de inmersión temporal para la micropropagación de Aztekium hintonii. Expociencias Nacional México D.F. 13 p.

Quispe A, Zavala D, Posso M, Rojas J y Vaisberg A, (2007). Efecto citotóxico de Annona muricata (guanábana) en cultivo de líneas celulares de adenocarcinoma gástrico y pulmonar", CIMEL, Vol. 12, 1, pp. 19-22.

Razdan. M. (2002) Introduction to plant Tissue Culture. Second. Edi,pp4-375

Ríos, D.; Corrales, D. (2003). Caracterización de la Guanábana Elita, chirimoya y otras anonáceas promisorias para Colombia. Rev Biotec.3: pp. 180-2000. 
Risdianto, H., Harjati, S., Niloperbowo, W. y Setiadi, T. (2007). "The Influence of Immersion Period on Laccase Production by Marasmius sp. in A Modified Temporary Bioreactor", The 20th International symposium on Chemical Engineering, Hambat National University, Daejeon, Korea

Sánchez, M.; Aguirreolea, J. (1996). Fisiología y bioquímica vegetal. Madrid. 49-90. MURILLO, J. Las Annonaceae de Colombia. Biota Colombiana. 2001. 2: 49-58

Santos A. F.; Santana A. E. G. (2001). Molluscicidal properties of some species of Annona. Phytomedicine. Vol. 8(2), pp. 115-120. SKOOG, D. A.; HOLLER, F. J.; NIEMAN, T. A.; (1995). Principios de Análisis Instrumental. Quinta edición. McGraw-Hill/Interamericana de España, S. A. U. España. pp. 731-809

Takayama S, Akita M (1994) Practical aspects of bioreactor application in mass propagation of plants. En: AK Hvoslef-Eide y W Preil (Eds.). Liquid Culture Systems for in vitro Plant Propagation, pp. 61-78. Springer. Dordrecht 